\title{
Glokalna e-mobilizacja: (naprawdę) nowe media narzędziem obywatelskiej mobilizacji
}

\section{Wprowadzenie}

Dierwsza dekada XXI wieku to okres znaczących zmian wzorców wykorzystania Internetu. Współczesna sieć (jeszcze kilka lat temu chętnie nazywana Siecią 2.0) funkcjonuje w dużej mierze na podstawie reguł uogólnianych czasem jako architektura uczestnictwa, na którą składają się przede wszystkim: 1) sieci społeczne - elementy społecznościowe są coraz ważniejszym składnikiem rosnącej liczby witryn; 2) treści generowane przez użytkowników; 3) społeczne media (social news).

Tak skonstruowany (czy raczej: na bieżąco rekonstruowany) Internet funkcjonuje również jako medium, za pomocą którego prowadzona jest szeroko pojęta obywatelska działalność mobilizacyjna. W artykule zostaną nakreślone główne sposoby wykorzystania nowych technologii komunikacyjnych przez politycznych aktywistów w ich działalności organizacyjno-mobilizacyjnej. Co ciekawe, te same schematy organizacyjne (metody, narzędzia) coraz częściej służą do przygotowywania działań, takich jak: demonstracje i protesty, oraz przedsięwzięć w ramach kampanii wyborczych. 


\section{Obywatelska mobilizacja w społeczeństwie sieci - definicje}

Użyte w tytule artykułu pojęcie e-mobilizacji (czy mobilizacji online) można zdefiniować za Andrew Chadwickiem [2006: 114] jako wykorzystywanie nowych mediów przez grupy interesu i ruchy społeczne do celów politycznej rekrutacji, organizacji i kampanii. Zakres podmiotowy definicji (pojęcia grupy interesu i ruchu społecznego) jest czytelny, warto jednak zauważyć, że w najnowszej naukowej refleksji nad ruchami społecznymi często wiąże się funkcjonowanie nowych ruchów społecznych (jak nazywają je Alberto Melucci i Anthony Giddens) czy ruchów społecznych ery informacji (termin Manuela Castellsa) z nowymi mediami, technologią kluczową dla owych struktur społecznych.

Obywatelska działalność mobilizacyjna stanowi absolutny priorytet w aktywności ruchów społecznych przełomu drugiego i trzeciego tysiąclecia. Współczesna działalność polityczna coraz częściej przybiera formę zbiorowych akcji, mających na celu forsowanie grupowych interesów lub dążenie do wspólnego celu, prowadzonych poza sferą ustanowionych instytucji [Giddens 2007: 464]. Manuel Castells [zob. 2007], umieściwszy ruchy społeczne w centrum swojej koncepcji społeczeństwa sieci, definiuje je jako celowe działania zbiorowe, których wynikiem - zarówno w wypadku zwycięstwa, jak i niepowodzenia - jest przekształcanie wartości i instytucji społeczeństwa [Castells 2008: 19].

Dla takich formacji społecznych ${ }^{1}$ kluczowa staje się ich zbiorowa tożsamość - interaktywna i dzielona definicja, konstruowana przez jednostki (bądź - na wyższym poziomie organizacyjnym - przez grupy) i dotycząca orientacji na działania, a także możliwości i ograniczeń, odnoszących się do owych działań [Melucci 1996: 70]. Ruchy oparte na zbiorowej tożsamości podejmują aktywność określaną mianem „polityki tożsamości" [Melucci 1996: 186-190], kwestionując, w dużej mierze poprzez media, tradycyjne tryby reprezentacji z ich językowymi i kulturowymi kodami, wykorzystywanymi do definiowania tego, co polityczne. $Z$ kolei właśnie nacisk na tożsamość, wartości kulturowe oraz proces nadawania (i redefiniowania) zna-

1 Do nowych ruchów społecznych zalicza się przede wszystkim ruchy feministyczne, praw człowieka, ekologiczne, na rzecz praw mniejszości seksualnych, antynuklearne, związkowe, pacyfistyczne [Giddens 2007: 464; Castells 2003: 163]. 
czeń sprawia, że dla nowych ruchów społecznych kluczowego znaczenia nabierają proces komunikowania oraz zasoby informacyjne.

Nowe media okazują się w tym kontekście technologią najważniejszą dla nowych ruchów społecznych - według Manuela Castellsa [2003: 159-163] Internet szybko stał się ich niezastąpionym składnikiem z trzech powodów. Po pierwsze, nowe ruchy społeczne koncentrują się wokół wartości kulturowych, dlatego fundamentalną sprawą staje się dla nich przekazywanie wartości i mobilizowanie się w ich obronie; rozwijają się dzięki systemom komunikacyjnym - głównie Internetowi i mediom tradycyjnym - bo tylko za ich pośrednictwem mogą dotrzeć do tych, którzy podzielają ich system wartości, i w ten sposób wpływać na świadomość całego społeczeństwa.

Po drugie, współczesne ruchy społeczne działają jako luźne, często powstające ad hoc koalicje - nowe media stały się podstawowym środkiem służącym ich organizowaniu. Dzięki Internetowi ruch może być i różnorodny, i zdolny do podejmowania skoordynowanych działań. Internet umożliwia toczenie ciągłej debaty w ramach ruchu, która go nie paraliżuje, ponieważ w ramach każdego węzła można relatywnie swobodnie konfigurować sieć sympatii i celów.

Po trzecie, źródłem władzy są dzisiaj w coraz większej mierze globalne sieci, a nie instytucje państwa. Ruchy społeczne, chcąc im dorównać zasięgiem, uciekają się do symbolicznych akcji, aby uzyskać wpływ na globalne media. Innymi słowy, globalizacja ruchów społecznych jest odrębnym i dużo ważniejszym zjawiskiem niż sam ruch przeciwko globalizacji.

Nowe media stały się więc kluczowym zasobem dla ruchów społecznych - funkcjonalnym narzędziem podtrzymywania ich formy organizacyjnej (globalne usieciowione koalicje), a także technologią sprzyjającą podtrzymywaniu zbiorowych tożsamości je (ruchy) konstytuujących (poprzez wewnętrzną komunikację i zewnętrzną działalność medialną). Jednocześnie specyfika Internetu sprawia, że do pewnego stopnia może on równoważyć mniejszy, z punktu widzenia podmiotów, przeciwko którym aktywiści podejmują działania, poziom innych zasobów, takich jak pieniądze czy dostęp do mediów.

Wracając do podmiotowego zakresu przytoczonej powyżej definicji e-mobilizacji, przyjęcie perspektywy sensu largo sprawia, że w mobilizacji online będą zawierać się również działania zapośredniczone przez nowe me- 
dia, prowadzone w ramach kampanii wyborczych ${ }^{2}$. Choć zamieszczone poniżej rozważania będą dotyczyć przede wszystkim obywatelskiej działalności niezwiązanej z e-kampaniami, to zostaną zaakcentowane istotne zbieżności w używaniu nowych mediów przez nowe ruchy społeczne i sztaby wyborcze w kampanii wyborczej w USA w 2008 roku - przełomowej z perspektywy wykorzystania nowych mediów jako narzędzi politycznej mobilizacji.

Przyjmując perspektywę przedmiotową, w przypadku e-mobilizacji nowe media występują w podwójnej roli: 1) funkcjonują jako narzędzie komunikacji, 2) stanowią nowe środowisko działania aktywistów i całych ruchów społecznych czy sztabów wyborczych. E-mobilizacja (nazywana również cyfrowym aktywizmem, kiedyś cyberaktywizmem) to działalność, którą można za Sandorem Veghem [2003: 72] podzielić na trzy rodzaje zazębiających się działań: 1) aktywność polegająca na podnoszeniu świadomości i rzecznictwie/wyrażaniu poparcia (awareness/advocacy); 2) działania organizacyjno-mobilizacyjne (organization/mobilization); 3) szeroko pojęte bezpośrednie działania prowadzone tylko w Internecie, głównie hakerskie (action/reaction).

Jednocześnie warto podkreślić, że dynamika i kierunki przemian funkcjonowania Internetu na początku XXI wieku jednoznacznie sprzyjają aktywizmowi: funkcjonalna jest zarówno architektura uczestnictwa i społecznościowy charakter Internetu (sieci społeczne umożliwiają szybką i skuteczną koordynację działań i wymianę informacji), jak i jego rosnąca mobilność (laptopy, komórki, inne urządzenia przenośne). Właśnie dlatego tytuł artykułu zawiera pojęcie naprawdę nowych mediów - Internet końca pierwszej dekady XXI wieku różni się w sposób znaczący (stopień upowszechnienia, możliwości dostępu, wzorce wykorzystania) od Internetu z połowy lat 90 . poprzedniego stulecia.

\section{Glokalny charakter obywatelskiej mobilizacji online}

Współczesna e-mobilizacja to coraz częściej działalność prowadzona online i, co wykażą przytoczone poniżej przykłady, jednocześnie obliczona

${ }^{2}$ W literaturze przedmiotu obywatelską mobilizację online i e-kampanie, dla analitycznego porządku, z reguły omawia się osobno (niewykluczone jednak, że sytuacja wkrótce ulegnie zmianie w wyniku doświadczeń amerykańskiej kampanii wyborczej przed wyborami w 2008 r.). 
na wywołanie określonych skutków offline. Wbrew prognozom formułowanym dekadę temu, użytkownicy Internetu i równocześnie odbiorcy komunikatów publikowanych przez aktywistów są nawoływani za pośrednictwem nowych mediów do podejmowania działań poza siecią. Z czego wynika to skupienie na akcjach zakończonych działaniami offline?

Z doświadczenia aktywistów wynika, że cyfrowe zapośredniczenie aktywności obywatelskiej (w szczególności działanie prowadzone tylko online) wcale nie musi być z punktu widzenia aktywizmu funkcjonalne. Chodzi o tak zwany efekt taniej komunikacji (cheap talk effect), polegający na lekceważeniu obywatelskich działań prowadzonych tylko online przez adresatów owych działań, ponieważ koszty uczestnictwa w takich działaniach (maile, elektroniczne petycje) są często bliskie zeru. Do tego dochodzi możliwość manipulacji: w internetowych kampaniach mobilizacyjnych relatywnie łatwo ukryć ich rzeczywistych autorów i ich interesy. Tego typu akcje bywają nazywane astroturf campaigns, "kampaniami sztucznej trawy"3. To zjawisko jest szersze niż aktywizm i starsze niż Internet - przedsięwzięcia imitujące działalność oddolną, w rzeczywistości będące działalnością korporacji czy produktami sztabów wyborczych. Takie postrzeganie Internetu jako medium komunikatów obywatelskich sprawia, że np. członkowie amerykańskiego Kongresu wyżej cenią sobie niezautomatyzowaną korespondencję, jak listy w całości napisane odręcznie, niż tę powstałą na bazie szablonów czy maile [Chadwick 2006: 121]. Z tego powodu niektóre organizacje sugerują swoim członkom i sympatykom pisanie maili własnymi słowami (bez korzystania z gotowych wzorców) albo wprost namawiają do odręcznego pisania (jak Amnesty International) 4 .

Glokalność jest terminem, po który sięga Manuel Castells, opisując globalny zasięg współczesnych ruchów społecznych i ich jednoczesny silny związek ze sferą lokalności. Najbardziej wpływowe ruchy społeczne są głęboko zakorzenione w środowiskach lokalnych i zarazem nastawione na

${ }^{3}$ Astroturf campaigns albo astroturfing to nieprzetłumaczalna gra słów: kampanie astroturfowe (AstroTurf jest rodzajem sztucznej trawy) to kampanie udające kampanie grassroots. Kampanie sztucznej trawy to narzędzie wykorzystywane m.in. przez korporacje i zorganizowane grupy interesu do działań lobbingowych i promocyjnych [Lyon, Maxwell 2004: 561-597].

${ }^{4}$ Co charakterystyczne, Amnesty International długo była niechętna umieszczaniu w sieci wszystkich informacji na temat organizowanych przez nią Pilnych Akcji - do 2002 r. tylko sekcje szwedzka i amerykańska Al zamieszczały w Internecie sugerowaną treść petycji i adresy odpowiednich władz [Lebert 2003: 221]. 
uzyskanie globalnego oddziaływania. Potrzebują legitymizacji i oparcia, które daje im zależność od lokalnych grup, lecz nie poprzestają na lokalnych działaniach, by nie tracić zdolności wpływania na prawdziwe źródła władzy [Castells 2003: 162-163].

W tym artykule termin glokalny zostanie wykorzystany również $\mathrm{w}$ trochę innym kontekście. Glokalną e-mobilizację można zdefiniować jako wykorzystywanie nowych mediów przez aktywistów w ich działaniach organizacyjno-mobilizacyjnych jednocześnie na dwóch przenikających się poziomach: globalnym i lokalnym. Chodzi więc o wykorzystanie nowych mediów - w tym mobilnych - do zdalnej (czyli prowadzonej poprzez rozproszoną, zdecentralizowaną sieć) koordynacji zbiorowych działań, jednocześnie mających miejsce w ściśle określonej fizycznej przestrzeni (przestrzeniach). W przypadku tego artykułu chodzi o szeroko pojętą działalność o charakterze obywatelskim.

Światowy aktywizm szybko zaadaptował nowe media do własnych działań. Wyciągnąwszy wnioski z doświadczeń neozapatystów i ich zwolenników ${ }^{5}$, w sposób przełomowy (zasięg i formy wykorzystania) użyto nowych mediów podczas dwóch koordynowanych globalnie akcji. Jedną były protesty podczas szczytu Światowej Organizacji Handlu w Seattle w listopadzie 1999 roku. Drugą - o kilka miesięcy wcześniejszy (18 czerwca 1999 r.) Karnawał Przeciwko Kapitalizmowi (Carnival Against Capitalism - CAC), demonstracja w Londynie, w której kilka tysięcy ludzi przemaszerowało ulicami miasta, protestując przeciwko przebiegowi ekonomicznej globalizacji (podobne demonstracje odbyły się tego dnia w kilkudziesięciu miastach świata).

Oba wydarzenia wykazują szereg podobieństw organizacyjnych, powielanych w pierwszej dekadzie XXI wieku przy przygotowywaniu i koordynacji obywatelskich wystąpień o charakterze glokalnym na całym świecie, między innymi demonstracji przeciw wojnie w Iraku w lutym 2003 roku (jednego z największych tego typu protestów w historii, obejmującego ponad 600 miast w ponad 60 państwach, w których protestowało około 10 milionów ludzi).

${ }^{5}$ Niedługo po wybuchu powstania w meksykańskim regionie Chiapas w 1994 r., skierowanego przeciwko rządowi w Meksyku, w wielu miastach świata zorganizowano demonstracje poparcia dla Ejercito Zapatista de Liberacion Nacional (EZLN), składającej się głównie z indiańskich chłopów (nazywanych zapatystami bądź neozapatystami). Do organizacji i koordynacji demonstracji wykorzystano m.in. nowe media [Ronfeldt et al. 1998: 51-53]. 
Zarówno CAC, jak i antyszczyt w Seattle charakteryzował zdecentralizowany, oddolny "lekki" styl organizacyjny, odznaczający się jednocześnie działaniami na wysokim poziomie koordynacji. Ten typ organizacji działań grupowych Alan Scott i John Street [2000: 226] nazywają zorganizowaną spontanicznością, mając na myśli formę organizacji i koordynacji działań zbiorowych podejmowanych offline z wykorzystaniem mediów umożliwiających komunikację na poziomie online, charakteryzującą się równocześnie: wysoką płynnością form organizacyjnych i decentralizacją dowodzenia, przy jednoczesnym efektywnym realizowaniu określonych celów, na bieżąco modyfikowanych w razie potrzeby. Naomi Klein [2008: 53], publicystka i obserwatorka wielu antyglobalistycznych protestów, w podobny sposób postrzega ich organizację. Opisując antyszczyty (m.in. w Seattle, Waszyngtonie, Vancouver, Londynie), twierdzi, że zostały one przygotowane zgodnie z zasadami skoordynowanej decentralizacji: „zamiast tworzyć wspólny front, niewielkie grupy aktywistów i aktywistek otoczyły swój cel ze wszystkich stron. I zamiast budować skomplikowane narodowe i międzynarodowe struktury biurokratyczne, naprędce stworzono struktury tymczasowe" ${ }^{\prime \prime}$.

Glokalnie organizowane wystąpienia (jak CAC czy antyszczyt w Seattle) zostają, po pierwsze, poprzedzone globalnymi przygotowaniami prowadzonymi online, odbywającymi się poprzez specjalnie założone witryny ${ }^{7}$, czaty, fora internetowe, grupy dyskusyjne czy - coraz częściej - serwisy społecznościowe, wszystkie bardzo aktywne również podczas samych protestów.

Po drugie, nowe media z powodzeniem funkcjonują także jako narzędzie organizacji i koordynacji działań w skali mikro: bardzo ściśle związanych z określonym kontekstem lokalnym. Jackie Smith [2002: 220], analizując repertuar działań podejmowanych przez protestujących w Seattle, wykorzystanie przez nich nowych mediów do działań organizacyjno-koordynacyjnych (określone przez nią mianem elektronicznego aktywizmu), uznaje za najistotniejszą innowację w zakresie form protestu użytych podczas antyszczytu.

6 Jednocześnie Naomi Klein [2008: 58] uważa, że decentralizacja jest bardzo funkcjonalna w przypadku organizacji bieżących działań, ale utrudnia wypracowywanie bardziej strategicznych decyzji czy rozwiązań.

7 Taki charakter miała www.j18.org, nawiązująca do daty - 18 czerwca - odbycia się Karnawału Przeciwko Kapitalizmowi. 
Doświadczenia pierwszej dekady XXI wieku pokazały, że ten model stał się swoistym standardem: uczestnicy demonstracji (działający w ramach wykształcających się oddolnie zadaniowych grup o specjalistycznym charakterze) na bieżąco komunikują się ze sobą poprzez telefony komórkowe i laptopy. Już podczas wydarzeń w Seattle w 1999 roku wykorzystano przenośne urządzenia radiowe i policyjne skanery, by koordynować działania i reagować na zmieniającą się sytuację zewnętrzną (wyprzedzano posunięcia policji). Co więcej, nowe media umożliwiają aktywistom prowadzenie działań w ukryciu, co dodatkowo utrudnia służbom porządkowym szybkie reagowanie. Gdy udało się policji i FBI w Seattle rozbić mobilną sieć komunikacji protestujących, ci bardzo szybko dokonali jej rekonstrukcji m.in. dzięki zakupom nowych telefonów komórkowych [Smith 2002: 215-221]. Przedstawiciel londyńskiej policji przyznał na łamach prasy po Karnawale Przeciwko Kapitalizmowi: „Nie wiemy, kto za tym stoi. Ale osiągnęli, co zaplanowali. Nasze zasoby były mocno nadwyrężone. Podejmowali taktyczne decyzje, odpowiadając na nasze posunięcia" [Scott, Street 2000: 232-233].

Nowe media funkcjonują nie tylko jako efektywne narzędzie organizacji globalnie przygotowywanych i precyzyjnie planowanych protestów. Okazują się skuteczne również przy spontanicznej, przygotowywanej w krótkim czasie obywatelskiej mobilizacji. Przykładem tego typu protestu jest People Power II, wielka demonstracja ponad miliona ludzi w centrum Manili na Filipinach w styczniu 2001 roku, wyrażająca sprzeciw obywateli tego państwa wobec niepowodzenia procesu impeachmentu prezydenta Josepha Estrady ${ }^{8}$. Ogromny udział w koordynacji spontanicznego wystąpienia miały telefony komórkowe (głównie SMS-y) - popularne na Filipinach z powodu wadliwych linii naziemnych, wolnej poczty i drogich komputerów, a także przeludnionych miast [Rafael 2003: 400-403]. Pokojowe protesty nie były jedynym powodem zmiany władzy w kraju (Estrada stracił poparcie armii), ale odegrały istotną rolę: komórki umożliwiły obywatelom organizowanie się w spontaniczne tłumy przy jednoczesnym koordynowaniu wzajemnych działań, które nie stanowią typowych zachowań tłumu [Rafael 2003: 415].

Howard Rheingold, analizujący m.in. protesty w Manili i Seattle, określa je mianem inteligentnego tłumu (smart mob), nazywając tak samoor-

${ }^{8}$ Po czterech dniach obywatelskich protestów Joseph Estrada został zmuszony do rezygnacji. 
ganizujący się system informacyjny, w którym jednostki i małe grupy wymieniają między sobą istotne dla nich informacje9 ${ }^{9}$ Sieciowa infrastruktura nowych mediów umożliwia tego typu zdecentralizowaną, spontaniczną komunikację w szerszej społecznie skali, która z kolei stanowi warunek konieczny powodzenia akcji takich jak demonstracja w Manili czy innych, podobnych do niej pod względem sposobu organizacji (oddolna spontaniczna mobilizacja, polegająca na dynamicznej agregacji działań jednostek).

W ten sposób przygotowany i przeprowadzony został pierwszy etap obywatelskich protestów przeciwko Rewolucyjnym Siłom Zbrojnym Kolumbii (FARC). Ponad milion Kolumbijczyków wyszło 4 lutego 2008 roku na ulice Bogoty (kolejne tysiące na ulice innych miast Kolumbii i świata), aby wyrazić swój sprzeciw wobec bojówek FARC, prowadzących działania zbrojne na terenie kraju i przetrzymujących w dżungli setki zakładników. Protesty rozpoczął 33-letni inżynier Oscar Morales, zakładając na początku lutego 2008 roku grupę na serwisie społecznościowym Facebook „A Million Voices Against FARC". W ciągu doby grupa miała 3000 członków, szybko zdobyła 250 tysięcy, pod koniec 2008 roku liczyła 300 tysięcy osób.

Internet (struktury komunikacyjne serwisu społecznościowego) okazał się efektywnym narzędziem wsparcia oddolnie organizujących się obywatelskich grup nacisku i ruchów ideologicznych, wykształcających się w ramach społeczeństwa obywatelskiego i jednocześnie sytuujących się poza politycznym mainstreamem [Neumayer, Raffl 2008: 2-3]. Wykorzystując termin Benedicta Andersona, można powiedzieć, że nowe media stanowią narzędzie o wysokim potencjale do podtrzymywania/rozwijania wspólnot wyobrażonych: komunikacja w ramach zapośredniczonych komputerowo sieci społecznych oznacza m.in. dzielenie się znaczeniami przez członków tych sieci, konstytuującymi zbiorowe tożsamości i praktyki. W tym sensie protest rozpoczęty na Facebooku wykorzystał i wzmocnił niechęć do FARC, narastającą w coraz większej części kolumbijskiego społeczeństwa obywatelskiego [Neumayer, Raffl 2008: 3-4].

Jak wspomniano powyżej, mechanizmy e-mobilizacji wypracowywane przy dużym udziale ruchów społecznych zostały (w zróżnicowanym zakresie) wykorzystane przez sztaby wyborcze kandydatów konkurujących

9 Książka Howarda Rheingolda na temat inteligentnych tłumów [zob. Rheingold 2002]. Witryna Rheingolda poświęcona zagadnieniom z książki: www.smartmobs.com. 
o urząd prezydenta USA w wyborach w 2008 roku. Szczególnie skuteczna okazała się kampania Baracka Obamy, który umieścił strategię internetową w samym centrum swojej kampanii, czyniąc z rozwiązań społecznościowych również atut organizacyjny ${ }^{10}$, realizowany w dużej mierze poprzez specjalnie utworzony na tę okoliczność serwis społecznościowy MyBarackObama.com (MyBO). Które schematy obywatelskiej e-mobilizacji zostały powielone w sieciowej kampanii wyborczej Baracka Obamy?

Po pierwsze, MyBO okazał się doskonałym narzędziem wyborczej organizacji/mobilizacji z powodu wysokiego potencjału do mikrotargetingu: witryna działała jako baza statystycznych informacji o ludziach popierających demokratycznego kandydata, poprzez którą jednym kliknięciem można było segregować i tworzyć listy według kryteriów geograficznych, demograficznych, stopnia zaangażowania itp.

Po drugie, kluczem do kampanijnej skuteczności MyBO był nacisk na podejmowanie działań offline. Jak podkreślał Joe Trippi, „mogłeś się zalogować i ściągnąć nazwiska, adresy i numery telefonów setki ludzi z sąsiedztwa, którzy mieli głosować, albo 40 osób z twojej dzielnicy, którzy jeszcze nie podjęli decyzji. "Tu macie ulotkę, wydrukujcie ją i zanieście im«. To ty, na własnym komputerze, we własnym domu, drukujesz i ściągasz. I oni wszyscy świetnie się spisali" [Talbot 2008 ${ }^{11}$.

Po trzecie, to właśnie poprzez MyBO podejmowano większość kampanijnej działalności mobilizacyjnej - duża część akcji zapoczątkowanych poprzez witrynę (online), jak i dzięki niej (offline) była zdecentralizowana, w tym, co okazało się istotne, zdecentralizowana również na poziomie planowania poszczególnych działań. Sztab zachęcał zwolenników Obamy do wykorzystywania aplikacji online do organizowania lokalnych kampanii według ich własnych pomysłów.

Po czwarte, sztab Baracka Obamy skutecznie realizował politykę umieszczania wizerunku kandydata na zróżnicowanych platformach medialnych. Duże znaczenie miał wirusowy charakter rozpowszechnianych informacji, dzięki któremu materiały audiowizualne demokratycznego kandydata mogły omijać tradycyjne filtry skupione w mediach głównonurtowych i docierać do dużych grup zainteresowanych nimi wyborców

10 Sztab Obamy zatrudnił m.in. 24-letniego wówczas Chrisa Hughesa, współzałożyciela serwisu Facebook.

11 MyBO dostarczał nawet propozycji tematów rozmów z sąsiadami na temat głosowania na Obamę. 
dzięki spontanicznej, oddolnej cyrkulacji, zgodnej z horyzontalnym modelem przepływu informacji medialnych. Niektóre z przekazów umieszczanych w sieci przez ludzi popierających Obamę szybko zyskały ogromną popularność [Talbot 2008; Brownstein 2008] ${ }^{12}$.

Sztab Baracka Obamy zresztą oddawał inicjatywę samym internautom, którzy chętnie przygotowywali wiele z najpopularniejszych kampanijnych materiałów wideo - wykorzystywano entuzjazm i umiejętności obywateli do umożliwionego przez nowe media konstruowania (i dekonstruowania w przypadku parodii i wszelkiego rodzaju remiksów) treści kulturowych o charakterze politycznym. Co ciekawe, ten sposób użycia nowych mediów również stanowi powielenie (opisanej poniżej) medialnej polityki nowych ruchów społecznych.

\section{Dwa obiegi medialne a obywatelska e-mobilizacja}

We wszystkich przywołanych powyżej przykładach obywatelskiej glokalnej e-mobilizacji nowe media zostały wykorzystane m.in. jako narzędzie omijania zapośredniczenia przez media głównonurtowe, funkcjonujących w ich tradycyjnej roli informacyjnych gate-keeperów. Sieciowy, horyzontalny i bardzo zróżnicowany formalnie charakter komunikacji zapośredniczonej komputerowo predysponuje Internet do funkcjonowania w roli medium oddolnej, spontanicznej komunikacji, prowadzonej poza tradycyjnymi obiegami medialnymi: obywatele mający dostęp do sieci za jej pośrednictwem komunikują się między sobą relatywnie swobodnie, poprzez mechanizmy społecznego filtrowania, dzieląc się i komentując medialne przekazy (zarówno fragmenty przekazów konstruowanych przez media głównonurtowe, jak i powstających spontanicznie przekazów oddolnych).

Jednocześnie jednak doświadczenia ostatniej dekady wskazują, że najbardziej skuteczne e-kampanie opierają się na wykorzystywaniu obu

12 Umieszczony w licznych wersjach w serwisie YouTube teledysk do zmiksowanej przemowy Obamy "Yes We Can" (z udziałem wielu amerykańskich celebrytów, wyprodukowany przez hip-hopowego producenta Will.i.ama) został obejrzany przynajmniej kilkanaście milionów razy, przemowa Obamy na temat kwestii rasy - ponad 4 miliony razy. Przekazy multimedialne Johna McCaina i Hillary Clinton również cieszyły się relatywnie wysoką popularnością (szczególnie w kontekście podobnych prób podejmowanych podczas wcześniejszych wyborów), ale nie osiągnęły stopnia popularności filmów i teledysków produkowanych przez zwolenników senatora z Illinois. 
systemów medialnych: systemu mediów tradycyjnych (prasa, radio, telewizja), zdominowanych oczywiście przez głównonurtowe przedsiębiorstwa medialne, oraz systemu nowych mediów, w którym mieszają się treści generowane przez medialny mainstream z treściami tworzonymi przez samych użytkowników Internetu. Aktywiści wykorzystują więc Internet jako narzędzie konstruowania agendy mediów tradycyjnych, czemu niewątpliwie sprzyja proces konwergencji szeroko pojętego systemu medialnego (we wszystkich jej wymiarach: technologicznym, kulturowym, ekonomicznym). Już pod koniec lat 90 . XX wieku nowe media zaczęły funkcjonować w roli, w której - w rosnącym stopniu - funkcjonują do dzisiaj: działają jako przestrzeń, w której aktywiści umieszczają przekazy informacyjne, adaptowane przez media tradycyjne do ich potrzeb. Ten mechanizm znajduje odzwierciedlenie w strategii większości protestów (działania zwolenników neozapatystów, CAC, kolejne antyszczyty), ich nacisku na spektakl, gest, kpinę, stanowiąc dobry przykład polityki działań symbolicznych, chętnie wykorzystywanej przez światowy aktywizm jako sposobu zewnętrznej komunikacji ruchu z mediami i (również za ich zapośredniczeniem) z opinią publiczną na szczeblach od lokalnego po globalny [Scott, Street 2000: 226].

Także podczas protestów przeciw FARC w Kolumbii w 2008 roku kluczowe - na pewnym etapie protestu - okazały się media tradycyjne. Rozwijającą się w ramach Facebooka informacją o planowanej akcji zainteresowały się media głównonurtowe (kolumbijska prasa, radio, telewizja w szczególności największy kolumbijski dziennik „El Timepo"), rozpowszechniając ją wśród całego kolumbijskiego społeczeństwa [Neumayer, Raffl 2008: 4] ${ }^{13}$. Na skuteczność e-mobilizacji wpływają więc określone wzorce społeczne, związane ze środowiskiem, w ramach których jest podejmowana (jak na przykład stopień upowszechnienia nowych mediów). Z ilościowego punktu widzenia, w lutym 2008 roku znaczenie Facebooka w życiu całego społeczeństwa w Kolumbii było marginalne - serwis społecznościowy i internetowa infrastruktura okazały się tylko narzędziem potrzebnym na pierwszym etapie protestu, później toczącego się już w znacznej mierze offline. Jednocześnie jednak to w dużej mierze dzięki

${ }^{13}$ Istotne znaczenie miało również poparcie dla protestu wyrażone przez przywódców opinii i polityków (z prezydentem Alvarem Uribe na czele). 
nowym mediom akcja nabrała charakteru globalnego: przeciw FARC protestowano też poza Kolumbią (m.in. w Europie, Stanach, Japonii).

Nowe media stanowią więc skuteczne narzędzie mobilizacji, ale do popularyzacji określonych działań media tradycyjne wciąż są z reguły niezbędne (choć oczywiście stopień zależności efektywności e-mobilizacji od mediów tradycyjnych zmienia się: maleje wraz ze stopniem upowszechniania nowych mediów). Z kolei, gdy dostęp do Internetu i odpowiednie kompetencje komunikacyjne przestają być społecznym przywilejem, wtedy potencjał mobilizacji online rośnie. Pod koniec pierwszej dekady XXI wieku Internet coraz częściej był wykorzystywany do omijania pośredników i docierania z określonymi rodzajami przekazu (przekazów) bezpośrednio do grup docelowych konkretnych działań aktywistów. Co więcej, niektóre społeczne wzorce wykorzystania Internetu sprzyjają rosnącemu potencjałowi e-mobilizacji, prowadzonej z ominięciem mediów tradycyjnych: w 2009 roku podwoiła się popularność materiałów wideo oglądanych w sieci (z ok. 15 miliardów w styczniu do ponad 33 miliardów w grudniu 2009 r.). Jednocześnie wydłuża się ogon zjawiska: coraz więcej podmiotów (również szeroko pojętych aktorów politycznych) tworzy własne kanały wideo, a użytkownicy sieci coraz chętniej z nich korzystają [Tsur 2010]. Potwierdzają to wyniki badań Pew Internet \& American Life Project [2008: 7-8], dotyczące kampanii wyborczej w USA w 2008 roku, podczas której już około 1/3 Amerykanów docierała do pierwotnych, nieprzefiltrowanych przez media tradycyjne, komunikatów politycznych.

\section{Podsumowanie}

Glokalna e-mobilizacja stanowi rodzaj działalności łączącej ze sobą dwa poziomy funkcjonowania aktywizmu: online i offline. Dynamika rozwoju nowych mediów (architektura uczestnictwa, mobilny dostęp) sprawia, że dobrze wykorzystane stają się one funkcjonalnym narzędziem dla szeroko pojętych podmiotów obywatelskiego aktywizmu. Zdecentralizowana, sieciowa struktura nowych mediów sprzyja elastyczności ruchów społecznych i dobremu wykorzystaniu potencjału ich członków w działalności online. Jednocześnie nowe media mogą zwiększać efektywność mobilizacji i organizacji działań offline: Internet i mobilne media umożliwia- 
ją koordynację grup organizujących się w konkretnych miejscach, a także zapewniają wysoki poziom współpracy między sieciami ruchów w skali globalnej. Co więcej, nowe media są skutecznym narzędziem, umożliwiającym aktywistom organizowanie i wykorzystywanie alternatywnego do głównonurtowego medialnego obiegu informacyjnego na wszystkich (od lokalnego po globalny) poziomach działania.

Na koniec warto sformułować dwa zastrzeżenia. Po pierwsze, glokalna e-mobilizacja nie musi dotyczyć jedynie akcji konfrontacyjnych i tak spektakularnych jak wspomniane uliczne protesty, może polegać na organizacji i koordynacji działań w mniejszej skali lub o niekonfrontacyjnym charakterze. Mniejszą skalę mają na przykład organizowane w miastach całego świata pod hasłem "masa krytyczna” zgromadzenia rowerzystów protestujących przeciwko ich lekceważeniu przez kierowców i lokalne władze. Z kolei zupełnie niekonfrontacyjnym działaniem są odbywające się corocznie na całym świecie organizowane przez Amnesty International maratony pisania listów, będących wyrazem poparcia na rzecz konkretnych więźniów z całego świata ${ }^{14}$.

Po drugie, nowych mediów jako narzędzi mobilizacji (w wymiarze globalnym, lokalnym bądź przenikających się obu) nie można postrzegać deterministycznie. Doświadczenia pierwszej dekady XXI wieku z Iranu, Chin czy Kuby wskazują, że demokratyzujący potencjał nowych mediów jest wciąż jednak dość skutecznie tłumiony w państwach niedemokratycznych. Nowe media funkcjonują więc coraz częściej jako warunek konieczny udanej obywatelskiej mobilizacji, jednocześnie będąc niestety warunkiem dalece niewystarczającym.

\section{Bibliografia}

Castells Manuel. 2003. Galaktyka Internetu. Refleksje nad Internetem, biznesem i społeczeństwem. Poznań: Rebis.

Castells Manuel. 2007. Społeczeństwo sieci. Warszawa: Wydawnictwo Naukowe PWN.

${ }^{14}$ W celu uniknięcia opisanego wcześniej efektu taniej komunikacji są to listy pisane odręcznie i wysyłane pocztą analogową. 
Castells Manuel. 2008. Siła tożsamości. Warszawa: Wydawnictwo Naukowe PWN.

Chadwick Andrew. 2006. Internet Politics. States, Citizens, and New Communication Technologies. New York-Oxford: Oxford University Press.

Giddens Anthony. 2007. Socjologia. Warszawa: Wydawnictwo Naukowe PWN.

Klein Naomi. 2008. Mury i wyłomy, czyli bariery i szanse. Doniesienia z linii frontu debaty o globalizacji. Warszawa: Wydawnictwo Naukowe PWN.

Lebert Joanne. 2003. Writing Human Rights Activism. [w:] M. McCaughey, M. D. Ayers (red.). Cyberactivism. Online Activism in Theory and Practice. New York-London: Routledge.

Lyon T., Maxwell J. 2004. Astroturf: Interest Group Lobbying and Corporate Strategy. „Journal of Economics and Management Strategy" vol. 13, no. 4, s. 561-597.

Melucci Alberto. 1996. Challenging Codes: Collective Action in the Information Age. Cambridge: Cambridge University Press.

Rafael Vicente. 2003. The Cell Phone and the Crowd. „Public Culture” 15 (3), s. 399$-425$.

Rheingold Howard. 2002. Smart Mobs. The Next Social Revolution. Cambridge: Perseus Books.

Ronfeldt David, Arquilla John, Fuller Graham, Fuller Melissa. 1998. The Zapatista "Social Netwar" in Mexico. Washington: RAND.

Scott Allan, Street John. 2000. From Media Politics to E-Protest. The use of popular culture and new media in parties and social movements. "Information, Communication \& Society" vol. 3 (2), s. 215-240.

Smith Jackie. 2002. Globalizing Resistance: The Battle of Seattle and the Future of Social Movements. [w:] J. Smith, H. Johnston (red.). Globalization and Resistance. Oxford: Rowman \& Littlefield Publishers, Inc.

Vegh Sandor. 2003. Classyfying Forms of Online Activism. The Case of Cyberprotests against the World Bank. [w:] M. McCaughey, M. D. Ayers (red.). Cyberactivism. Online Activism in Theory and Practice. New York-London: Routledge.

\section{Źródła internetowe}

Brownstein Ronald. 2008. The First 21st-Century Campaign. „National Journal Magazine". http://www.nationaljournal.com/njmagazine/print_friendly.php?ID =cs_20080416_3324, 2.05.2010.

Neumayer Christina, Raffl Celina. 2008. Facebook for Protest? The Value of Social Software for Political Activism in the Anti-FARC Rallies. DigActive Research Se- 
ries. http://www.digiactive.org/wp-content/uploads/research1_neumayerraffl.pdf, 2.05.2010.

Pew Internet \& American Life Project. 2008. The internet and the 2008 election. Washington. http://www.pewinternet.org/pdfs/PIP_2008_election.pdf, 2.05.2010.

Talbot David. 2008. It's the Web, Stupid. Blog Technology Review Editors. http:// www.technologyreview.com/blog/editors/22171/, 2.05.2010.

Tsur Michal. 2010. Online Video. New tools are helping video become part of the fabric of the Web. „Technology Review". http://www.technologyreview.com/ web/25111/?ref=rss\&a=f, 2.05.2010. 